\title{
Effects of formoterol and ipratropium bromide on repeated cadmium inhalation-induced pulmonary inflammation and emphysema in rats
}

\author{
WenHui Zhang ${ }^{\mathrm{a}, *}$, Laurence Fievez ${ }^{\mathrm{b}}$, Fan Zhang ${ }^{\mathrm{c}}$, Esteban Cheu ${ }^{\mathrm{b}}$, Nadine Antoine ${ }^{\mathrm{b}}$, Catherine Delguste ${ }^{\mathrm{b}}$, \\ Yong Zhang ${ }^{\mathrm{d}}$, WeiFang Rong ${ }^{\mathrm{a}}$, Fabrice Bureau ${ }^{\mathrm{b}}$, Charles Advenier ${ }^{\mathrm{e}}$, Pascal Gustin ${ }^{\mathrm{b}}$ \\ a Department of Physiology, School of Medicine, Shanghai Jiaotong University, 280, Road Chong Qing Nan Lu, 200025 Shanghai, China \\ b Department for Functional Sciences B41, Faculty of Veterinary Medicine, University of Liège, 4000 Liège, Belgium \\ c Department of Pathology, School of Medicine, Shanghai Jiaotong University, China \\ d Department of Pharmacology, School of Medicine, Shanghai Jiaotong University, China \\ e UPRES EA 220, Hôpital Foch and Université Versailles Saint Quentin, Suresnes, France
}

\section{A R T I C L E I N F O}

\section{Article history:}

Received 28 January 2010

Received in revised form 11 July 2010

Accepted 24 August 2010

Available online 21 September 2010

\section{Keywords:}

Chronic pulmonary inflammation

Airspace enlargement

Formoterol

Ipratropium bromide

Cadmium

Matrix metalloproteinase

\begin{abstract}
A B S T R A C T
The anti-inflammatory properties of inhaled formoterol and ipratropium bromide, alone or in combination, were investigated in a rat model of chronic pulmonary inflammation with airspace enlargement induced by cadmium inhalation. At the end of the protocol, cadmium-induced increase of airway resistance was prevented by formoterol $(4 \mathrm{mg} / 30 \mathrm{ml})$ or ipratropium $(0.20 \mathrm{mg} / 20 \mathrm{ml})$. Formoterol elicited a significant decrease in total cell and neutrophil counts in bronchoalveolar lavage fluid as well as on the activity of gelatinase B (MMP-9), an enzyme strongly expressed in alveolar macrophages and epithelial cells. Additionally, a significant attenuation of the lung lesions characterized by inflammatory cell infiltration within the alveoli and the interstitium and a decrease in mean linear intercept were observed. Although ipratropium alone had no effects on the cadmium-induced pulmonary inflammation and emphysema, its combination with an inefficient concentration of formoterol $(1 \mathrm{mg} / 30 \mathrm{ml})$ showed a synergistic inhibitory effect on neutrophil and total cell counts as well as on the mean linear intercept associated with a synergistic inhibition on the MMP-9 activity. Gelatinase A (MMP-2) activity was not influenced by drug pretreatments. Neither macrophage metalloelastase (MMP-12) activity nor levels of cytokines IL-1 $\beta$, TNF- $\alpha$ and GM-CSF in bronchoalveolar lavage fluid were modified in rats chronically exposed to cadmium. No desensitization of $\beta_{2}$-adrenoceptors or cholinergic receptors on airway smooth muscles and inflammatory cells during the protocol was observed. In conclusion, formoterol alone or combined with ipratropium bromide partially protects the lungs against the chronic inflammation and airspace enlargement by reducing neutrophilic infiltration possibly via the inhibition of MMP-9 activity.
\end{abstract}

(C) 2010 Elsevier B.V. All rights reserved.

\section{Introduction}

$\beta_{2}$-adrenoceptor agonists and anticholinergic agents are used to manage airway obstruction in patients with chronic obstructive pulmonary disease (COPD). These drugs primarily exhibit their bronchodilating properties but also exert anti-inflammatory effects observed in vitro (Gosens et al., 2006; Hanania and Moore, 2004) and in animal models of acute pulmonary inflammation induced by various agents including cadmium, one of the numerous components of tobacco smoke and a toxic ambient pollutant (McQueen et al., 2007; Miyamoto et al., 2004; Razani-Boroujerdi et al., 2008; Zhang et al., 2010).

The long term effects elicited by these bronchodilators against chronic inflammatory processes and emphysema as observed in COPD patients have not been investigated in animal models. In patients with

\footnotetext{
* Corresponding author. Tel.: +86 21638465 90x776 446; fax: +86 21638465 $90 \times 776476$

E-mail address: i_zhangwenhui@yahoo.com.cn (W. Zhang).
}

COPD, the involvement of acetylcholine and its receptors has been described (Profita et al., 2005), and some anti-inflammatory effects of oxitropium and tiotropium have been reported in two clinical trials (Powrie et al., 2007; Profita et al., 2005). However, nothing is known about the impact of $\beta_{2}$-adrenoceptor agonists during the course of COPD (Hanania and Moore, 2004).The interaction of inhaled corticosteroids (ICSs) with one of these two types of bronchodilators or triple therapy has been proposed to better control COPD symptoms, including loss of elastic recoil and airway inflammation in patients with severe airway obstruction (Aaron et al., 2007; Cazzola and Dahl, 2004; Mortaz et al., 2008; Welte et al., 2009). These findings highlight the need to study the impact of these combinations on moderate inflammation, especially of bronchodilators which could also lead to synergistic or additive interactions (Jones, 2009).

Tobacco smoke is recognized with food as a main source of cadmium exposure for non-occupationally exposed population. This heavy metal is suspected to contribute to tobacco related lung diseases involving emphysema and neutrophilic inflammation resistant to 
corticosteroids, both associated with an imbalance between matrix metalloproteinases (MMPs) and tissue inhibitors of metalloproteinases (TIMPs) (Mannino et al., 2004). Similar pathological changes have been induced in rats exposed to cadmium inhalation (Kirschvink et al., 2005). In such diseases, the inhibition of MMP activity could thus be beneficial to prevent the lungs from inflammation and tissue remodelling due to the raising activity of these enzymes (Abboud and Vimalanathan, 2008; Corbel et al., 2000). The impact of bronchodilators on pulmonary MMP activity related to the pulmonary inflammation and emphysema is poorly documented. Recently, formoterol or ipratropium administrated alone has been found to inhibit the activity of gelatinase A (MMP-2) and gelatinase B (MMP-9) in rats exposed to a single dose of cadmium (Zhang et al., 2010). Whether this inhibitory effect can persist in a chronic inflammatory process remains unknown.

Thus, the aim of this study was to investigate the effects of formoterol and/or ipratropium bromide on pulmonary inflammation induced by repeated inhalation of cadmium in rats. In addition, we examined whether the expected anti-inflammatory effects of formoterol and/or of ipratropium bromide were associated with a modulation of MMP-2, MMP-9, macrophage metalloelastase (MMP-12) activity and their tissue inhibitors of metalloproteinase-1 (TIMP-1) and tissue inhibitors of metalloproteinase-2 (TIMP-2) which could also contribute to protective effects against emphysema.

\section{Materials and methods}

\subsection{Animals}

The study was approved by the Animal Ethical Committee of the University of Liège. Male Sprague-Dawley rats $(n=113)$ weighing between 300 and $350 \mathrm{~g}$ were obtained from the University's animal breeding unit. They were housed in the animal facilities of the laboratory for at least $24 \mathrm{~h}$ before the beginning of a three day training period with the plethysmograph and had free access to water and food.

\subsection{Study design and experimental protocols}

In the first day of the experimental protocol, animals were placed in the double chamber plethysmograph (Buxco Electronics, Inc., France) for pressure signals analysis by using BioSystem XA (Buxco Research System, USA) and determination of specific airway resistance. Then they were placed in an exposure chamber (length $\times$ width $\times$ height: $58 \mathrm{~cm} \times 38 \mathrm{~cm} \times 34 \mathrm{~cm}$ ) to be exposed to drugs and cadmium. An ultrasonic nebulizer (Ultraneb 2000, Devilbiss, Somerset, USA) was used to give an aerosol output at a rate of $6 \mathrm{ml} / \mathrm{min}$ as described by Kirschvink et al. (2005). In two groups, animals were first pretreated with solutions of two different concentrations of formoterol (1 mg/ $30 \mathrm{ml}$ or $4 \mathrm{mg} / 30 \mathrm{ml}$ ) before being immediately exposed in the same exposure chamber to a cadmium solution $\left(0.1 \% \mathrm{CdCl}_{2}\right)$ for $60 \mathrm{~min}$ (group $\mathrm{F} 1+\mathrm{Cd}$ and $\mathrm{F} 4+\mathrm{Cd}$ respectively; $\mathrm{n}=6$ per group). In two other groups, animals were pretreated with a solution of ipratropium bromide $(0.20 \mathrm{mg} / 20 \mathrm{ml}$ ) (group $\mathrm{I}+\mathrm{Cd} ; \mathrm{n}=6$ ) or with a combination of both formoterol ( $1 \mathrm{mg} / 30 \mathrm{ml})$ with ipratropium bromide $(0.20 \mathrm{mg} /$ $20 \mathrm{ml}$ ) (group $\mathrm{F} 1+\mathrm{I}+\mathrm{Cd} ; \mathrm{n}=6$ ) before cadmium administration. Formoterol and ipratropium bromide solutions were nebulized during 30 and 20 min respectively. When combined, formoterol was firstly nebulized (30 $\mathrm{min}$ ) immediately followed by ipratropium bromide (20 min). The same procedure was performed in animals pretreated with the same drugs but finally exposed to saline instead of cadmium ( 4 groups; $\mathrm{n}=6$ per group) for $60 \mathrm{~min}$. Concentrations of drugs and duration of nebulization were determined from a previous study demonstrating the protective effects of these drugs against a single dose cadmium-induced acute pulmonary inflammation (Zhang et al., 2010). This exposure procedure was repeated 3 times per week during 5 weeks.
Three cadmium-exposed control groups were investigated in parallel. Before inhalation of the cadmium solution, animals of these groups were exposed to vehicle used to dissolve the drugs $(0.1 \%$ DMSO solution of $\mathrm{NaCl} 0.9 \%)$ during $20 \mathrm{~min}, 30 \mathrm{~min}$ or $50 \mathrm{~min}(\mathrm{n}=6$ per group). As the duration of the pretreatment period with the vehicle had no influence on the response to the cadmium, all the data from the cadmium-exposed animals were pooled to obtain a single cadmium control group (group $\mathrm{Cd}, \mathrm{n}=18$ ). Finally a sham group (group $\mathrm{NaCl}, \mathrm{n}=6$ ) underwent the same protocol for 110 min with the corresponding vehicles ( 50 min with $0.1 \%$ DMSO in $0.9 \% \mathrm{NaCl}$ solution followed by a saline inhalation for $60 \mathrm{~min}$ ).

The rats were sacrificed $24 \mathrm{~h}$ after their last exposure by a lethal intraperitoneal injection of $200 \mathrm{mg} / \mathrm{kg}$ pentobarbital. Bronchoalveolar lavage was performed by flushing $8 \mathrm{ml}$ of saline two times successively in the right lung through a cannula located in the main bronchus. The liquid was then collected for subsequent bronchoalveolar lavage fluid analysis, whereas an approximately $50 \mathrm{mg}$ sample of left lung was cut down for the lung wet-to-dry weight ratio determination while the remaining tissue was fixed for histological examination, especially for the measurement of airspace enlargement.

\subsection{Measurement of lung function}

After being placed for $30 \mathrm{~min} /$ day into the double chamber plethysmograph (Buxco Electronics, Inc., France) on three consecutive training days, each animal underwent measurements of the baseline value of specific airway resistance by using BioSystem XA (Buxco Research System, USA) for signals analysis. A 5 min baseline recording was performed before the first exposure as well as $30 \mathrm{~min}$ after the last exposure, a period from which the bronchodilatory effects of formoterol and ipratropium occurred. The average within 5 min was calculated, and the changes of the specific airway resistance were expressed as percentages of increased baseline of specific airway resistance.

\subsection{Bronchoalveolar lavage fluid analysis}

\subsubsection{Cytological analysis and determination of protein content in} bronchoalveolar lavage fluid

Bronchoalveolar lavage fluid was centrifuged for $15 \mathrm{~min}$ at $4{ }^{\circ} \mathrm{C}$ $(450 \mathrm{~g})$ and supernatant was fractioned into $1 \mathrm{ml}$ samples, which were kept at $-80^{\circ} \mathrm{C}$ for further analysis. Total and differential cell counts, and determination of protein content in bronchoalveolar lavage fluid were performed as described previously (Kirschvink et al., 2005). Briefly, a total cell count was performed using Thomas cell. $150 \mu \mathrm{l}$ of bronchoalveolar lavage fluid was used for differential cell count by cytospin centrifugation (Shandon, Pittsburgh, PA, USA) and May Grünwald Giemsa staining. Protein level in each bronchoalveolar lavage fluid sample was determined through spectrophotometric assay (Microprotein, Elitech Diagnostics, France).

\subsubsection{Determination of bronchoalveolar lavage fluid matrix metalloproteases activity}

The activity of MMP-2 and MMP-9 was detected by gelatin zymography as previously described (Kirschvink et al., 2005). The casein zymography was performed for detection of MMP-12 gelatinolytic activity. This experimental method can detect an activity corresponding to $1 \mu \mathrm{g}$ of enzymes after dilution. In brief, $10 \mu \mathrm{l}$ of supernatant of bronchoalveolar lavage fluid was added to Laemmli buffer at a 1:1 ratio. The samples were subjected to electrophoresis on $10 \%$ acrylamide SDS gels containing porcine skin gelatine (1\%, Sigma, St. Louis, USA) or $\alpha$-casein (1\%, Sigma, St. Louis, USA). After loading onto gelatin gels with standards, the gels were then washed twice in Triton X-100 $2 \%$ for $30 \mathrm{~min}$ followed by an incubation at $37{ }^{\circ} \mathrm{C}$ overnight. After staining with Coomassie blue and destaining, gelatinolytic activity appeared as unstained zones against a blue 
background. Quantification of MMP activity was performed by using NIH imaging software, and was analyzed with Scion imaging analysis program (Scion Corporation, Frederick, MA, USA). Results were expressed as average arbitrary units (AU) corresponding to pixel density $\times \mathrm{mm}^{2}$ for the bands of proteolysis normalized by the same value calculated for a known amounts of standard (human proenzyme MMP-9, human pro-enzyme MMP-2, oncogene, San Diego, CA, USA). As the latent and active bands were so close that it was difficult to accurately analyze these two forms of MMPs respectively, the latent and active bands were taken together for analysis. In the sham group, MMP-9 activity was sometimes undetectable. So a 0 value was attributed to the corresponding samples.

\subsubsection{Determination of bronchoalveolar lavage fluid TIMP activity}

The activity of TIMP-1 and TIMP-2 was measured by reverse gelatin zymography. Bronchoalveolar lavage fluid samples were concentrated by Speedvac evaporation and diluted in a non-reducing sample buffer. They were loaded onto gelatin gels and were subjected to electrophoresis on 15\% acrylamide SDS gels containing porcine skin gelatine (1\%; Sigma, St. Louis, MO, USA) and CHO supernatant rich in MMP-2 and MMP-9. After being washed twice in Triton X-100 2\% for $30 \mathrm{~min}$ and incubated at $37^{\circ} \mathrm{C}$ for $24 \mathrm{~h}$ in an activation buffer containing $50 \mathrm{mM}$ Tris- $\mathrm{HCl}(\mathrm{pH} 7.5)$ and $10 \mathrm{mM} \mathrm{CaCl}_{2}$, the gels were rinsed and stained for $30 \mathrm{~min}$ with Coomassie blue and destained for 120 min in a solution of $10 \%$ acetic acid and $20 \%$ methanol $(\mathrm{v} / \mathrm{v})$. The quantification of TIMP-1 and TIMP-2 activities was undergone just as that of MMP activities.

\subsubsection{Detection of cytokines and chemokines}

Though the activity and the source of cytokines could not be detected by sandwich ELISA, this method was used to analyze levels of IL-1 $\beta$, TNF- $\alpha$ and GM-CSF in bronchoalveolar lavage fluid according to the manufacturer's instruction (R\&D Systems, Abingdon, United Kingdom; Perbio Science, Erembodegem, Belgium). The minimum detectable dose (MDD) for IL- $1 \beta$ and TNF- $\alpha$ is less than $5 \mathrm{pg} / \mathrm{ml}$ respectively. For GM-CSF, the mean MDD is $1.8 \mathrm{pg} / \mathrm{ml}$.

\subsection{Lung histomorphometry, quantification of emphysema and measurement of lung wet-to-dry weight ratio}

After fixation under a constant pressure of $25 \mathrm{cmH}_{2} \mathrm{O}$, lungs were embedded in paraffin and 2-3 $\mu \mathrm{m}$ transversal slices were cut in the medial lung portion and stained with hematoxylin-eosin coloration. The lung fields ( 8 per rat) were randomly selected and care was taken to avoid regions containing pleura or large bronchi. The lung field (magnification: 200×) was digitalized using a numeric camera AxioCam (Zeiss, Germany) and KS 400 software (Axioplan 2 imaging, Zeiss, Germany). The enlargement of alveolar spaces was quantified by the measurement of the mean linear intercept ( $\mathrm{Lm}$ ) as described previously (D'Hulst et al., 2005). In brief, a grid with nine horizontal and vertical lines was superposed on the field, and the total length of each line divided by the numbers of alveolar wall intersected the test lines was defined as mean linear intercept.

The wet weight was measured on an electronic scale immediately after death. The tissues were then desiccated in an oven at $65{ }^{\circ} \mathrm{C}$ for $72 \mathrm{~h}$ to determine the dry weight.

\subsection{Immunohistochemical staining for MMP-9}

Owing to the high correlation of MMP-9 activity with other inflammatory and functional parameters in this model and due to the inhibitory effects of the pretreatments assessed in this study on the activity of this enzyme, immunohistochemical staining for MMP-9 was performed. Goat polyclonal antibody anti-MMP-9 recognizing the latent form of MMP-9 was used (Santa Cruz Biotechnology, Inc. Germany). Tissue sections were deparaffinized, rehydrated and then blocked with $1 \% \mathrm{H}_{2} \mathrm{O}_{2}$ in methanol for $10 \mathrm{~min}$ to reduce the endogenous peroxidase activity. After incubation with $5 \%$ albumin bovine serum for $30 \mathrm{~min}$ at room temperature, the tissue sections were incubated with primary antibody diluted 1:50 in phosphate-buffered saline solution (PBS) at $4{ }^{\circ} \mathrm{C}$ overnight. After removing the excess of primary antibody by PBS, the tissue sections were then treated with a rabbit anti-goat IgG biotinylated antibody (DakoCytomation, Denmark) followed by an incubation with horseradish peroxidaseconjugated streptavidin (DakoCytomation, Denmark) at $37{ }^{\circ} \mathrm{C}$ for 30 min respectively. The immunoreactivities of the lung tissue specimens were visualized by a diaminobenzidine (DAB) Kit (Wuhan Boster Biological Technology, LTD, China) according to the manufacturer's protocol. Finally, sections were counterstained with hematoxylin, dehydrated, and mounted. A negative control was performed in parallel on lung tissue sections of rats exposed to cadmium in the absence of incubation with primary antibody anti-MMP-9.

\subsection{Inhibition of functional and inflammatory responses to methacholine and cadmiun by formoterol and ipratropium bromide}

To determine inhibitory effects of formoterol and ipratropium on methacholine induced bronchoconstriction and whether desensitization of $\beta_{2}$-adrenoceptors or muscarinic receptors occurred after repeated administrations of these drugs, two additional tests were performed aiming to detect possible changes which could occur during a 5-week exposure period in the airway responsiveness to methacholine and in the anti-inflammatory effects elicited by both drugs.

2.7.1. Determination of airway responsiveness to methacholine after single and repeated administrations of formoterol or ipratropium bromide

Two groups of animals ( $\mathrm{n}=4$ per group) were treated as described above with formoterol $(4 \mathrm{mg} / 30 \mathrm{ml} ; 30 \mathrm{~min})$ or ipratropium $(0.2 \mathrm{mg} /$ $20 \mathrm{ml}$; $20 \mathrm{~min}$ ) respectively, 3 times a week for 5 weeks and the airway responsiveness to increasing concentrations of methacholine was measured one day before the first treatment (D-1). Briefly, each animal was placed in the plethysmograph and was exposed to a saline solution for $2 \mathrm{~min}$ immediately followed by a 5 -min post-saline baseline record of the specific airway resistance. Saline solutions containing increasing concentrations of methacholine from $4 \mathrm{mg} / \mathrm{ml}$ to $32 \mathrm{mg} / \mathrm{ml}$ were then successively nebulized during $2 \mathrm{~min}$, each administration being separated by a 10 -min recording. The mean increase in the specific airway resistance calculated over each of these periods was expressed as a percentage of the mean post-saline value. The same procedure was repeated $2 \mathrm{~h}$ after the first (D 0 ) and the last treatment with formoterol or ipratropium (W 5). The two last administrations of both drugs were performed at a 3 day interval in order to avoid any bioaccumulation. Animals from the control group were treated by the vehicle all over the 5 -week protocol. At the end of this period (W 5), the response to methacholine was measured before and $2 \mathrm{~h}$ after a single administration of formoterol or ipratropium.

\subsubsection{Measurement of the cadmium-induced acute pulmonary} inflammation after single and repeated administrations of formoterol or ipratropium bromide

Compared to the anti-inflammatory effects of a single administration of formoterol or ipratropium bromide against the acute cadmium-induced lung injuries reported in a previous study (Zhang et al., 2010), the anti-inflammatory properties of these drugs recorded in the present study appeared rather limited. To check whether this loss of effectiveness could be due to a desensitization process, the anti-inflammatory effects of both drugs against the acute pulmonary inflammation induced by a single dose of cadmium were investigated after a single or repeated bronchodilator administration. Two groups of animals ( $\mathrm{n}=5$ per group) were nebulized with formoterol ( $4 \mathrm{mg} /$ $30 \mathrm{ml})$ or ipratropium $(0.2 \mathrm{mg} / 20 \mathrm{ml})$ at the same rate, for $30 \mathrm{~min}$ or 
20 min respectively, 3 times a week for 5 weeks as described above. The two last administrations of both drugs were performed at a 3 day interval in order to avoid any bioaccumulation. Two additional groups $(n=5$ per group) were only exposed to vehicles during 5 weeks immediately followed by a single administration of formoterol or ipratropium. In a fifth group $(n=5)$, animals were only exposed to vehicle during $30 \mathrm{~min}, 3$ times a week during 5 weeks. In all groups, the animal were introduced in an exposure chamber immediately after the last pretreatment, and exposed to a single dose of cadmium $\left(\mathrm{CdCl}_{2} 0.1 \%\right)$ for $60 \mathrm{~min}$. A sham group $(\mathrm{n}=5)$ was designed in which animals were exposed to $\mathrm{NaCl}$ for 60 min after 5-week treatment with vehicle. They were sacrificed and the bronchoalveolar lavage was collected for cytological analysis as previously described (Zhang et al., 2010).

\subsection{Drugs and solution concentration selection}

Cadmium chloride, ipratropium bromide and methacholine were purchased from Sigma (St Louis, USA). Formoterol fumarate was obtained from Novartis (UK) and pentobarbital (Dolethal ${ }^{\circledR}$ ) from Vetoquinol (France). Cadmium chloride was prepared in saline to get a $0.1 \%$ solution. Formoterol fumarate and ipratropium bromide were prepared in vehicle $(0.9 \% \mathrm{NaCl}$ solution containing $0.1 \% \mathrm{DMSO})$, and methacholine was dissolved in saline.

To determine the concentrations of each compound further investigated in the final protocol, the bronchodilating effects induced by increasing concentrations of formoterol or ipratropium bromide were first determined in a preliminary study in healthy rats exposed to methacholine. Briefly, dose-response curves to inhaled increasing concentrations of methacholine solutions ranging from 12.5 to $100 \mathrm{mg} / \mathrm{ml}$ were first constructed using a method previously described (Kirschvink et al., 2007). The concentration of methacholine inducing a $200 \%$ increase of specific airway resistance was then selected for each animal and then, repeated before and after the inhalation of increasing concentration solutions of formoterol or ipratropium bromide. The lowest, middle and highest concentrations of formoterol corresponding to $20 \%, 50-60 \%$ and more than $80 \%$ relaxing effect respectively were selected. Three concentrations of ipratropium bromide inducing similar effects were selected by the same way. Depending on a previous study demonstrating the protective effects of these concentrations of drugs against a single dose cadmium-induced acute pulmonary inflammation (Zhang et al., 2010), the lowest and the highest concentrations of formoterol (1 mg/ $30 \mathrm{ml}$ and $4 \mathrm{mg} / 30 \mathrm{ml}$ ) and the highest concentration of ipratropium $(0.2 \mathrm{mg} / 20 \mathrm{ml})$ were finally selected and used in the present study.

\subsection{Statistical analysis of results}

All data were presented as mean \pm S.D., and were analyzed by SAS612 analysis program (SAS Institute Inc, Cary, NC, USA). One-way analysis of variance (ANOVA) was performed to analyze the differences between groups followed by a post-test using the Student-Newman-Keuls test for comparison between groups. The correlation analysis was performed by linear regression. The $\mathrm{P}<0.05$ was considered as statistically significant.

\section{Results}

\subsection{Chronic pulmonary inflammation and airspace enlargement induced by repeated cadmium inhalation}

The 5-week exposure to cadmium induced a chronic pulmonary inflammation characterized by a significant increase in total cell numbers in bronchoalveolar lavage fluid which was attributed to a marked increase in neutrophil and macrophage counts (Fig. 1A-C). Though no impact on the lung wet-to-dry weight ratio was noted
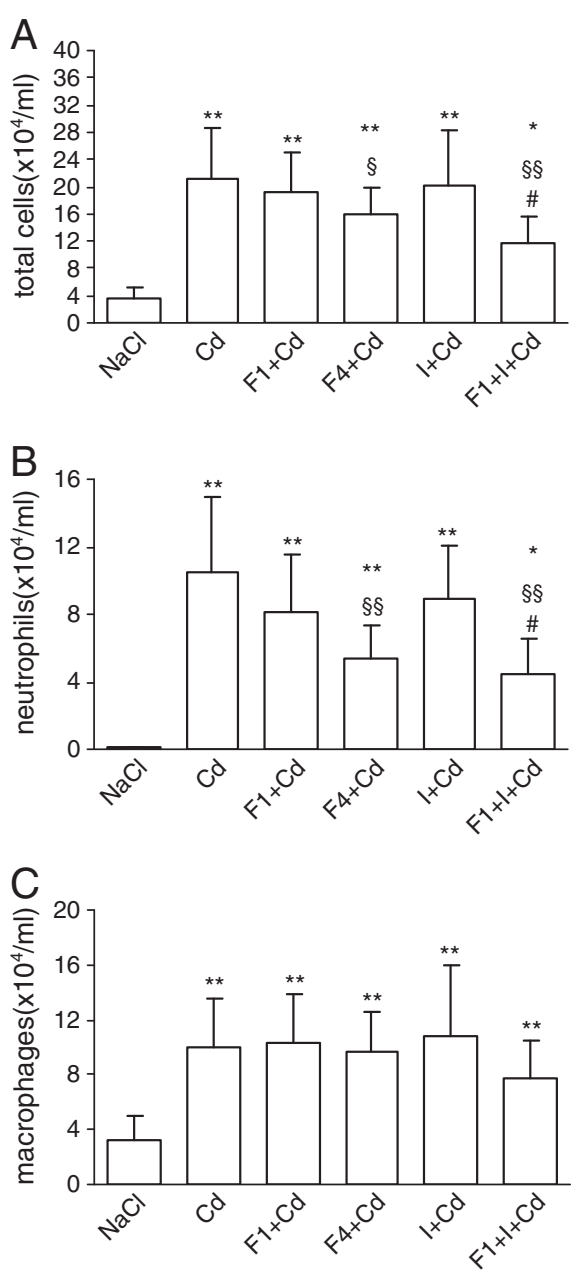

Fig. 1. Inflammatory cell counts in bronchoalveolar lavage fluid in rats pretreated with formoterol and/or ipratropium followed by repeated cadmium inhalation for 5 weeks. $\mathrm{NaCl}$ : sham group $(\mathrm{n}=6) ; \mathrm{Cd}: 0.1 \% \mathrm{CdCl}_{2}$ group $(\mathrm{n}=18) ; \mathrm{F} 1+C d, \mathrm{~F} 4+\mathrm{Cd}$ : animals pretreated with increasing concentrations of formoterol $(1 \mathrm{mg} / 30 \mathrm{ml} ; 4 \mathrm{mg} / 30 \mathrm{ml}$ respectively) followed by cadmium inhalation ( $\mathrm{n}=6$ per group); $\mathrm{I}+\mathrm{Cd}$ : animals treated with ipratropium bromide $(0.2 \mathrm{mg} / 20 \mathrm{ml})$ prior to cadmium inhalation $(\mathrm{n}=6) ; \mathrm{F} 1+\mathrm{I}+\mathrm{Cd}$ : animals pretreated with formoterol $(1 \mathrm{mg} / 30 \mathrm{ml})$ in combination with ipratropium bromide $(0.2 \mathrm{mg} / 20 \mathrm{ml})$ followed by cadmium inhalation $(\mathrm{n}=6)$. * indicates a significant difference in comparison with the sham group $\left({ }^{*} \mathrm{P}<0.05\right.$, ${ }^{* *} \mathrm{P}<$ $0.01) ; ~ \S$ indicates a significant difference in comparison with the cadmium-exposed group $(\S \mathrm{P}<0.05, \S \S \mathrm{P}<0.01)$; \# indicates a significant difference in comparison with $\mathrm{F} 1+\mathrm{Cd}$ group and $\mathrm{I}+\mathrm{Cd}$ group respectively $(\# \mathrm{P}<0.05)$.

(data not shown), a significant increase in total protein concentration in bronchoalveolar lavage fluid was detected in cadmium-exposed rats $(257.36 \pm 29.03 \mu \mathrm{g} / \mathrm{ml}$ versus $127.09 \pm 23.19 \mu \mathrm{g} / \mathrm{ml}, \quad \mathrm{P}<0.01)$, suggesting the occurrence of cadmium-induced inflammatory exudation and/or epithelial cell cytolysis. Histological examination confirmed the inflammatory cell infiltration, especially macrophages and neutrophils, within the alveoli. The alveolar septa became thicker and a multifocal parenchymal accumulation of inflammatory cells was also noted in alveolar interstitium. In addition, rats repeatedly exposed to cadmium had a dramatic and homogenous airspace enlargement as revealed by the significant increase in the mean linear intercept in the $\mathrm{Cd}$ group (Fig. 2A-B, E). Focal congestion and hemorrhage were also sometimes observed in some portions of the cadmium-exposed lungs. After a 5-week inhalation of saline, the baseline value of the specific airway resistance slightly decreased by comparison to the value measured before the beginning of the inhalation protocol ( $-18 \pm 25 \%)$, whereas a prominent augmentation in airway resistance was observed in cadmium-treated rats $(71 \pm 41 \%$, 

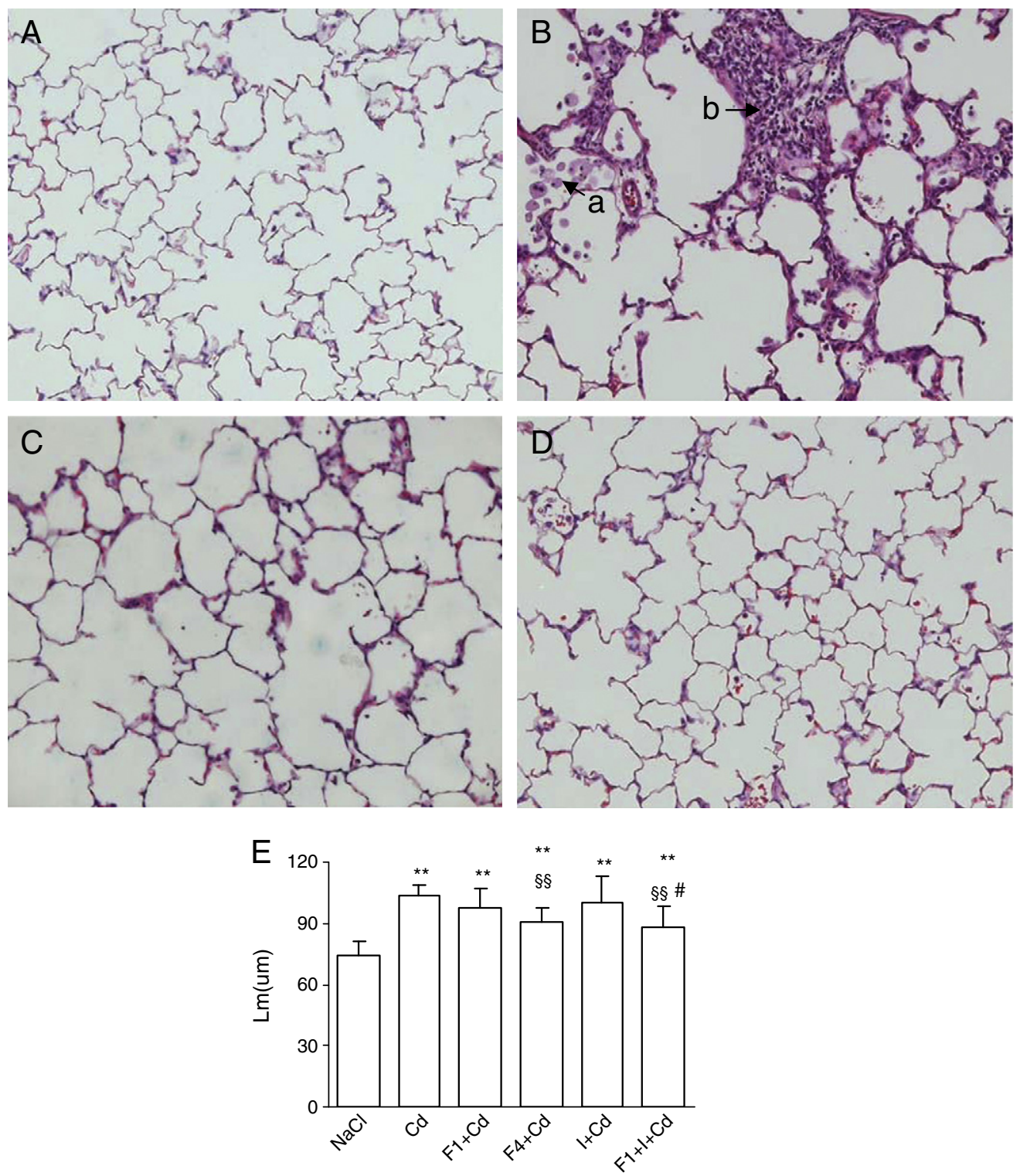

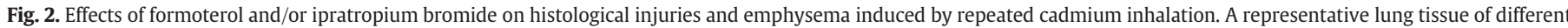

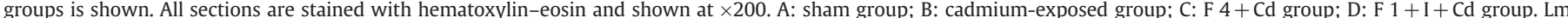

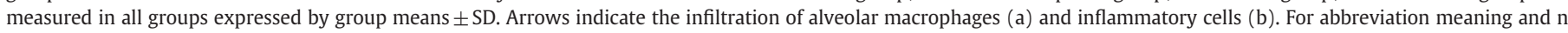

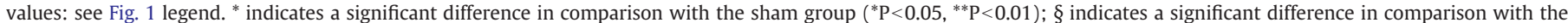
cadmium-exposed group $(\S \mathrm{P}<0.05, \S \S \mathrm{P}<0.01)$; \# indicates a significant difference in comparison with $\mathrm{F} 1+\mathrm{Cd}$ group and $\mathrm{I}+\mathrm{Cd}$ group respectively (\#P $<0.05$ ).

$\mathrm{P}<0.01$ ) (Fig. 3), suggesting an occurrence of airway obstruction in the present rat model.

MMP-2 gelatinolytic activity detected in the bronchoalveolar lavage fluid was significantly increased after 5 weeks of cadmium exposure (Fig. 4A, C). Cadmium inhalation also induced a marked increase in MMP-9 activity when compared with the sham group in which its activity was very low and even undetectable in some animals (Fig. 4B, D). As shown by Table 1, MMP-9 activity in the bronchoalveolar fluid was positively correlated with neutrophil and macrophage counts when animals from $\mathrm{NaCl}$ and $\mathrm{Cd}$ groups were pooled. MMP-9 activity was also strongly correlated with the mean linear intercept as well as with the specific airway resistance. However, MMP-2 activity was only correlated with the mean linear intercept and the number of macrophages in bronchoalveolar lavage fluid.

Given the strong correlations between MMP-9 and inflammatory parameters, and the fact that only MMP-9 activity was modulated by

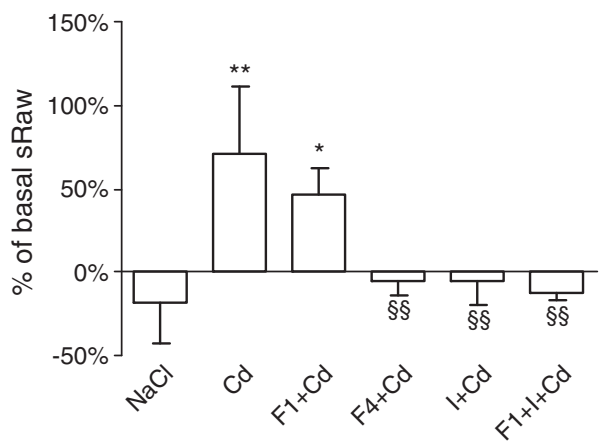

Fig. 3. Bronchodilatory protective effects of formoterol and/or ipratropium bromide in rats repeatedly exposed to cadmium. For abbreviation meaning and n values: see Fig. 1 legend. * indicates a significant difference in comparison with the sham group $\left({ }^{*} \mathrm{P}<0.05,{ }^{* *} \mathrm{P}<0.01\right) ; \S$ indicates a significant difference in comparison with the cadmium-exposed group $(\S \mathrm{P}<0.05, \S \S \mathrm{P}<0.01)$ 

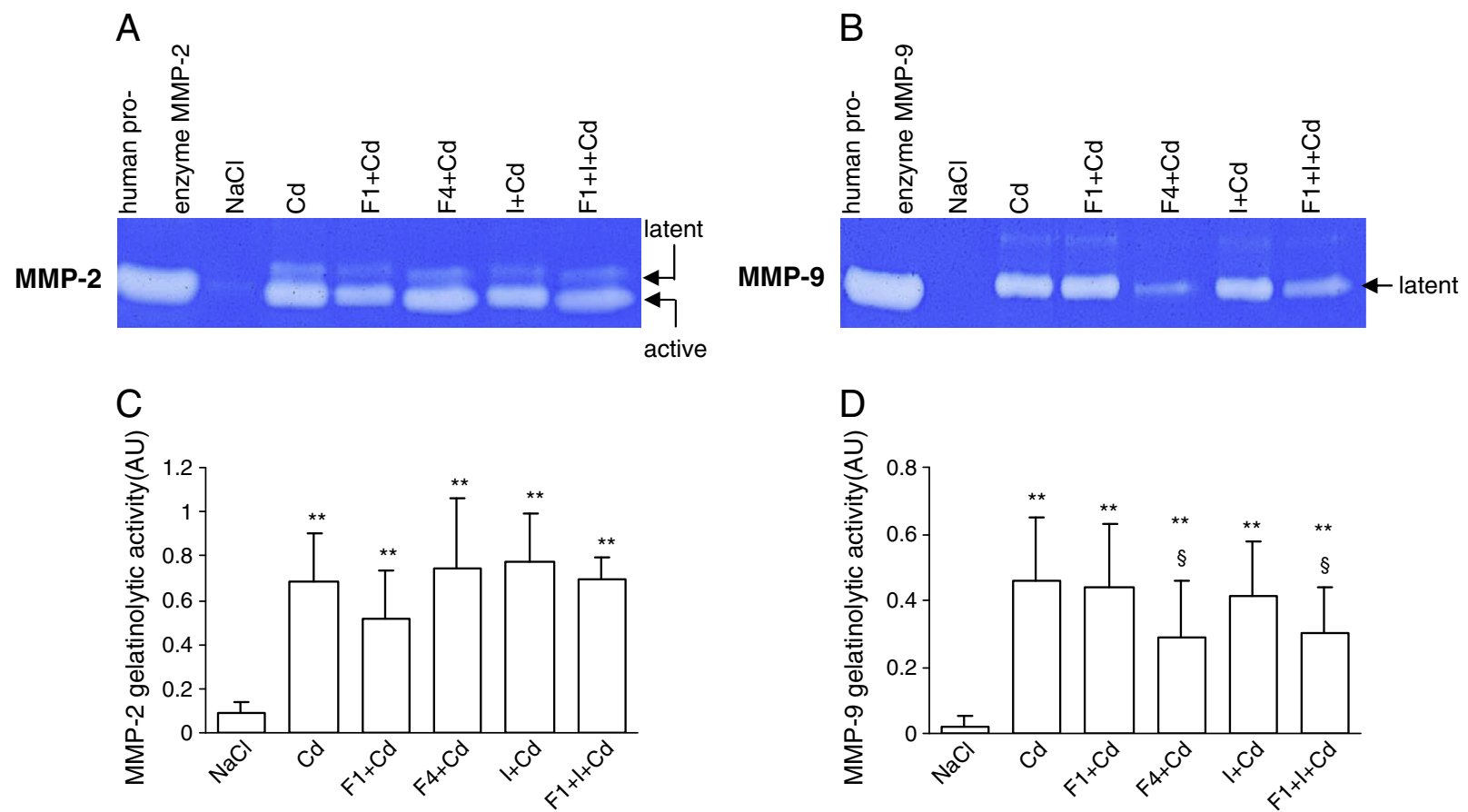

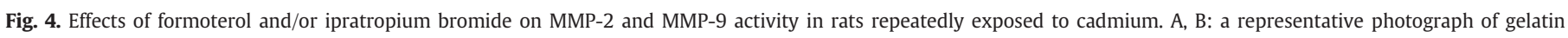

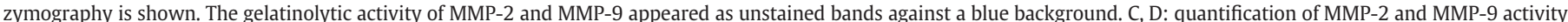

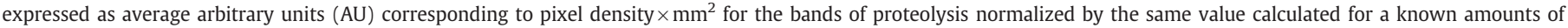

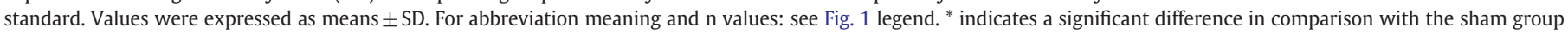
$\left({ }^{*} \mathrm{P}<0.05,{ }^{*} \mathrm{P}<0.01\right)$; § indicates a significant difference in comparison with the cadmium-exposed group $(\S \mathrm{P}<0.05)$.

drug administration, the expression of MMP-9 in lung tissue was analyzed by immunohistochemistry to identify the cell source secreting MMP-9. The immunohistochemical staining for MMP-9 showed a slight expression of MMP-9 in alveolar epithelial cells in the sham group, whereas a prominent staining in these cells as well as in alveolar macrophages was revealed in the cadmium-exposed group (Fig. 5B). The expression of MMP-9 was also detected in some inflammatory cells in the alveolar interstitium. These data are in agreement with the levels of MMP-9 activity in bronchoalveolar lavage fluid.

Neither significant effect of cadmium on MMP-12 activity nor on TIMP-1 and TIMP-2 activity was recorded (data not shown).

Repeated cadmium inhalation did not induce any significant variation in IL-1 $\beta$, TNF- $\alpha$, whilst GM-CSF in bronchoalveolar lavage fluid was very low or undetectable in vehicle- and cadmium-exposed rats (data not shown).

\subsection{Effects of formoterol on repeated cadmium inhalation-induced functional and inflammatory responses}

Formoterol exerted no impact on all functional and inflammatory parameters measured in healthy rats just as in the other animals undergoing the inhalation protocol for 5 weeks (data not shown), but prevented the lungs against cadmium-induced pulmonary inflammation and airspace enlargement when the high concentration $(4 \mathrm{mg} /$

Table 1

Coefficients of correlation between MMP activity with inflammatory and functional parameters in rats exposed to saline and cadmium for 5 weeks.

\begin{tabular}{lllll}
\hline & Neutrophils & Macrophages & Lm & sRaw \\
\hline MMP-2 & $0.50(\mathrm{NS})$ & $0.53^{\mathrm{a}}$ & $0.85^{\text {aaa }}$ & $0.51(\mathrm{NS})$ \\
MMP-9 & $0.69^{\text {aa }}$ & $0.57^{\mathrm{a}}$ & $0.87^{\text {aaa }}$ & $0.52^{\mathrm{a}}$ \\
\hline
\end{tabular}

Lm: mean linear intercept; sRaw: specific airway resistance.

NS: non significant, ${ }^{\mathrm{a}} \mathrm{P}<0.05$, ${ }^{\text {aa }} \mathrm{P}<0.01$, ${ }^{\text {aaa }} \mathrm{P}<0.001$.
$30 \mathrm{ml}$ ) was administrated 30 min prior each cadmium inhalation. Indeed, despite the ineffectiveness of the low concentration of formoterol $(1 \mathrm{mg} / 30 \mathrm{ml})$ on the inflammatory response induced by cadmium, pretreatment with the high concentration caused a significant decrease in neutrophil number in bronchoalveolar lavage fluid although a significant difference remained in comparison to the corresponding value obtained in the sham group. Macrophage number was not affected by formoterol (Fig. 1B-C). Though the high concentration of formoterol did not impair the increased protein concentration in bronchoalveolar lavage fluid in the $\mathrm{Cd}$ group $(272.56 \pm 77.67 \mu \mathrm{g} / \mathrm{ml})$, it exerted a significant reduction in inflammatory cell infiltration within the alveoli and in alveolar interstitium, accompanied with a significant decrease in mean linear intercept (Fig. 2C, E). As demonstrated by Fig. 3, the cadmium-induced significant increase in specific airway resistance was completely abolished by the pretreatment of the high concentration of formoterol which led to a $5 \pm 9 \%$ decrease compared with the value measured before the first inhalation within the same group $(\mathrm{P}<0.01)$.

No impact on MMP-2 activity was detected in rats pretreated with formoterol (Fig. 4A, C), while a marked attenuation of MMP-9 activity was observed when a high concentration of formoterol was administrated (Fig. 4B, D). The immunohistochemical assay showed the staining of MMP-9 mainly in alveolar macrophages and in epithelial and inflammatory cells (data not shown), just as in cadmium-exposed rats.

\subsection{Effects of ipratropium bromide alone and in combination with formoterol on repeated cadmium inhalation-induced functional and inflammatory responses}

Inhalation of ipratropium bromide in healthy rats exerted no significant effects on any parameters measured in this study (data not shown). The total cell numbers, including neutrophils and macrophages in bronchoalveolar lavage fluid, were not impaired by the pretreatment of ipratropium in cadmium-exposed rats (Fig. 1A-C). 


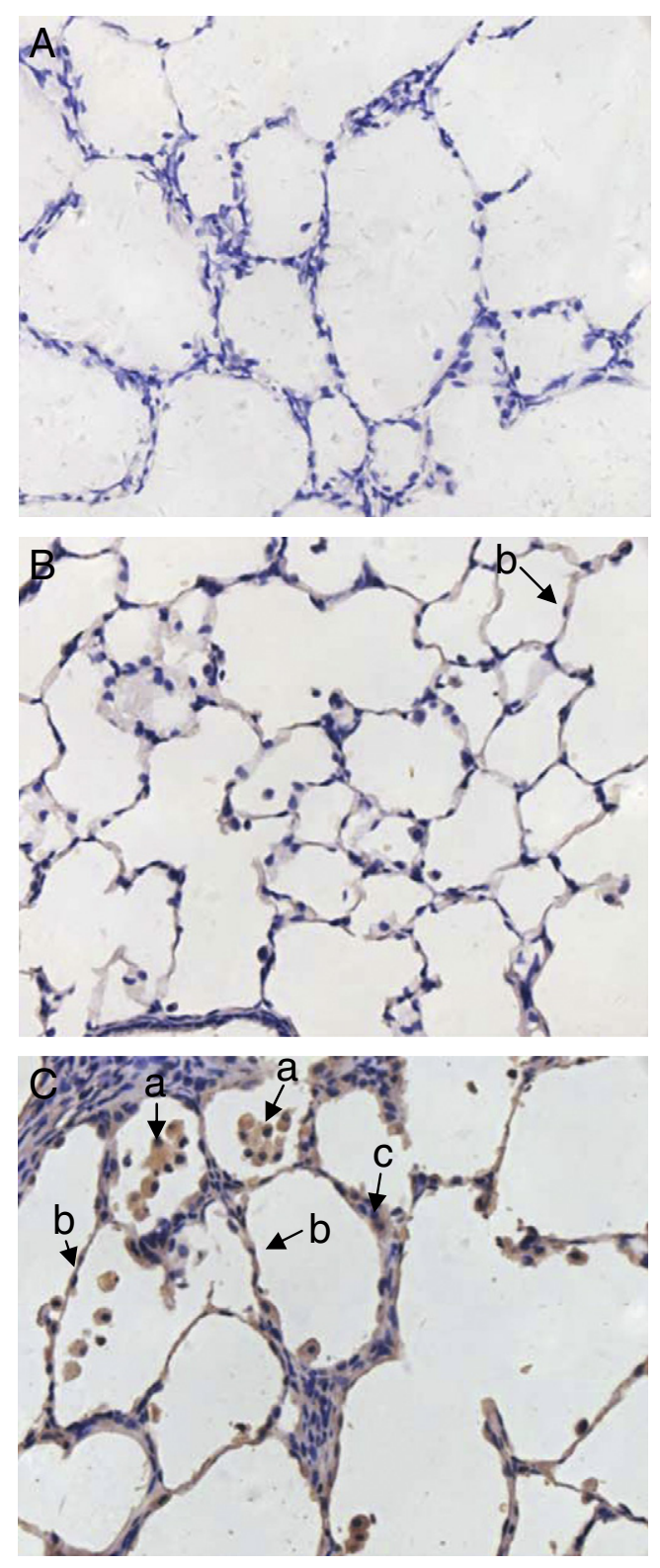

Fig. 5. Immunohistochemical staining for MMP-9 in lung tissue sections. A representative lung tissue of sham and cadmium-exposed groups is shown $(\times 400)$. A: a negative control was done using a section of a cadmium-exposed rat in the absence of primary antibody anti-MMP-9; B: a saline-exposed rat; C: a cadmium-exposed rat. Arrows indicate positive expression of MMP-9 in alveolar macrophages (a), epithelial cells (b) and inflammatory cells in lung tissue (c).

Ipratropium bromide also failed to prevent the elevated protein concentration in bronchoalveolar lavage fluid $(192.26 \pm 28.2 \mu \mathrm{g} / \mathrm{ml})$ and had no inhibitory effects on the development of airspace enlargement (Fig. 2E), and the increased MMP-2 and MMP-9 activity induced by cadmium inhalation (Fig. 4A-D). However, a significant reduction in the baseline value of the specific airway resistance was revealed after 5 weeks of pretreatment with ipratropium bromide $(5 \pm 14 \%, \mathrm{P}<0.01)$ (Fig. 3).

Formoterol with ipratropium, combined at inefficient concentrations ( $1 \mathrm{mg} / 30 \mathrm{ml}$ and $0.2 \mathrm{mg} / 20 \mathrm{ml}$ respectively) on inflammatory parameters and on the mean linear intercept, elicited a synergistic inhibitory effect on total cell and neutrophil counts in bronchoalveolar lavage fluid (Fig. 1A-B). Compared with the data obtained in cadmium-exposed rats, no inhibitory effects on macrophage count (Fig. 1C) and the increased protein concentration $(198.6 \pm 30.36 \mu \mathrm{g} /$ $\mathrm{ml}$ ) were detected in rats undergoing the combination administra- tion. Microscopic examination showed a synergistic protective effect against the airspace enlargement as illustrated by Fig. 2D. In some portions of lung tissue sections, the enlargement of airspace was markedly diminished. This impairment was confirmed by a significant decrease in mean linear intercept when compared with the rats pretreated by formoterol $1 \mathrm{mg} / 30 \mathrm{ml}$ or ipratropium bromide $0.2 \mathrm{mg} /$ $20 \mathrm{ml}$ respectively (Fig. 2E). The inflammatory infiltration within the alveoli and the parenchyma inflammatory accumulation induced by cadmium inhalation were also reduced as suggested by histological examination (Fig. 2D). The combination totally diminished the increased specific airway resistance induced by repeated cadmium exposure $(12 \pm 4 \%, \mathrm{P}<0.01)$, however, neither synergistic nor additive effects were found when compared with the data obtained in rats undergoing formoterol or ipratropium pretreatment alone (Fig. 3).

The zymography analysis showed that the combination of both drugs failed to prevent the cadmium-induced increase in MMP-2 activity, but induced a significant and synergistic decrease in MMP-9 activity (Fig. 4A-D).

\subsection{Determination of airway responsiveness to methacholine after single} and repeated administration of formoterol or ipratropium bromide

The inhalation of increasing concentrations of methacholine brought about a prompt and reversible bronchoconstriction in the healthy rats when measured the day before the beginning of the pretreatment with the bronchodilators (D-1), and a twofold or greater increase in the specific airway resistance was obtained when the highest concentration of methacholine $(32 \mathrm{mg} / \mathrm{ml})$ was administrated (Fig. 6A-B). As shown by Fig. 6, a single administration of formoterol or ipratropium bromide inhibited the response to methacholine (D 0 ). A similar bronchoprotective effect was found after a 5-week exposure (W 5) to both drugs administrated separately all over this period (Fig. 6A-B). The responses to methacholine in the control group after a 5-week exposure to saline and measured just before and after a single administration of formoterol or ipratropium were similar to those recorded in pretreated animals on D 0 and W 5 (data not shown).
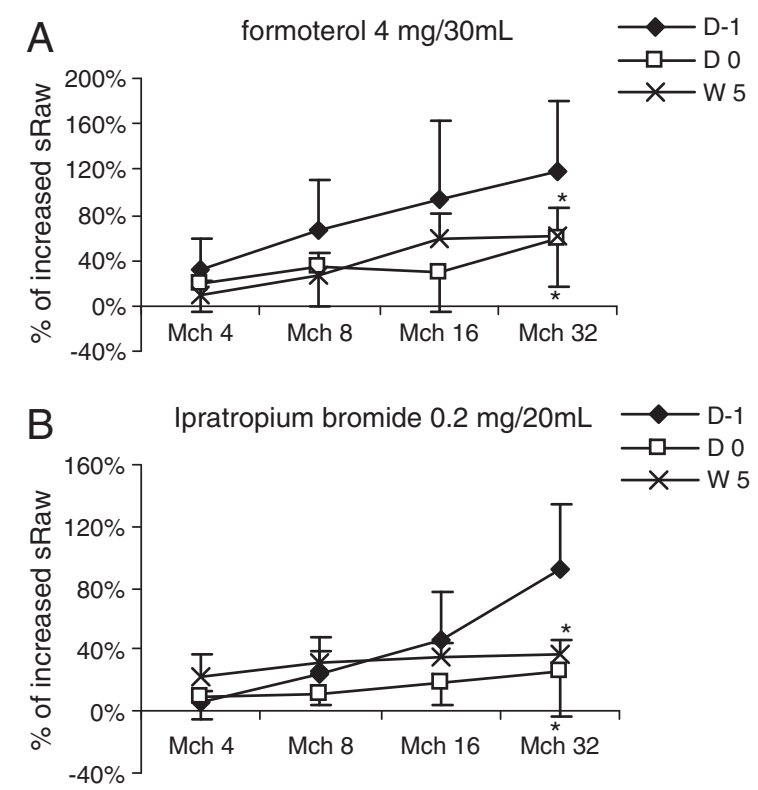

Fig. 6. Comparison of bronchoprotective effect of formoterol (A) or ipratropium bromide (B) administrated as a single dose or over 5 weeks against the airway responsiveness induced by the increasing concentrations of methacholine $(n=4$ per group). D-1: the day before the beginning of the inhalation protocol for 5 weeks. D 0 : the first day of the inhalation protocol for 5 weeks. W5: the end of the inhalation protocol for 5 weeks. ${ }^{*} \mathrm{P}<0.05$ compared with the corresponding value obtained at $\mathrm{D}-1$. 
Table 2

Comparison of the anti-inflammatory effects of formoterol or ipratropium bromide against a single dose of cadmium-induced acute pulmonary inflammation.

\begin{tabular}{|c|c|c|c|c|c|c|}
\hline & \multirow[t]{2}{*}{$\mathrm{NaCl}$} & \multirow[t]{2}{*}{$0.1 \% \mathrm{CdCl} 2$} & \multicolumn{2}{|c|}{ Single exposure } & \multicolumn{2}{|c|}{ 5-week exposure } \\
\hline & & & Formoterol & Ipratropium & Formoterol & Ipratropium \\
\hline Total cells $\left(\times 10^{4} / \mathrm{ml}\right)$ & $4.8 \pm 0.84$ & $43.8 \pm 26.1^{\mathrm{bb}}$ & $16.8 \pm 5.5^{\mathrm{a}}$ & $12.8 \pm 6.3^{\mathrm{aa}}$ & $16.4 \pm 3.8^{\mathrm{a}}$ & $19.2 \pm 3.7^{\mathrm{a}}$ \\
\hline Neutrophils $\left(\times 10^{4} / \mathrm{ml}\right)$ & $0.10 \pm 0.11$ & $13.3 \pm 6.6^{\mathrm{bb}}$ & $6.5 \pm 2.8^{\mathrm{a}}$ & $4.2 \pm 1.8^{\mathrm{aa}}$ & $6.7 \pm 1.2^{\mathrm{a}}$ & $6.1 \pm 1.5^{\mathrm{a}}$ \\
\hline Macrophages $\left(\times 0^{4} / \mathrm{ml}\right)$ & $4.5 \pm 0.72$ & $20.2 \pm 13.7^{\mathrm{bb}}$ & $10.3 \pm 2.8$ & $8.6 \pm 4.6$ & $9.7 \pm 2.8$ & $12.1 \pm 2.0$ \\
\hline
\end{tabular}

$\mathrm{NaCl}$ : sham group; animals exposed to $\mathrm{NaCl}$ for 60 min after 5 weeks of vehicle inhalation.

$0.1 \% \mathrm{CdCl} 2$ : animals exposed to $0.1 \% \mathrm{CdCl} 2$ for 60 min after 5 weeks of vehicle inhalation.

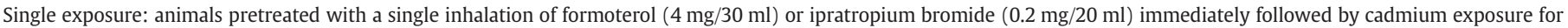
60 min after 5 weeks of vehicle inhalation.

5-week exposure: animals pretreated for 5 weeks with formoterol $(4 \mathrm{mg} / 30 \mathrm{ml})$ or ipratropium bromide $(0.2 \mathrm{mg} / 20 \mathrm{ml})$ followed by cadmium exposure for $60 \mathrm{~min}$.

The results are expressed as the mean $\pm \mathrm{SD}$.

${ }^{a} \mathrm{P}<0.05$, ${ }^{\text {aa }} \mathrm{P}<0.01$ compared with a single cadmium-exposed group; ${ }^{\mathrm{b}} \mathrm{P}<0.05$, ${ }^{\text {bb }} \mathrm{P}<0.01$ compared with the sham group.

\subsection{The cadmium-induced acute pulmonary inflammation after single or repeated administration of formoterol or ipratropium bromide}

The inhibitory effects on the cadmium-induced increase in total cell and neutrophil counts in bronchoalveolar lavage fluid in rats pretreated with a single inhalation of formoterol or ipratropium bromide are illustrated in Table 2. Similar anti-inflammatory effects were recorded in animals pretreated respectively with two bronchodilators for 5 weeks before being exposed to a single dose of cadmium (Table 2).

\section{Discussion}

The cigarette smoke-induced infiltration of inflammatory cells within the lung tissue is one of the most important characteristics of COPD which contributes to the airway obstruction and leads to emphysema (Molfino and Jeffery, 2007). The most relevant experimental model of COPD is based on the exposure of animals to cigarette smoke, the natural inducer of the disease. Due to the very long period necessary to obtained pulmonary emphysema, other agents including cadmium, suspected to contribute to tobacco related diseases, have been used to mimic the main pathological features of the disease (Hoidal et al., 1985; Zhang et al., 2010). Our previous study showed a chronic neutrophilic inflammation associated with pulmonary emphysema related to an increase in MMP-2 and MMP-9 activity in rats exposed to cadmium for 5 weeks (Kirschvink et al., 2005). These findings suggest that the present model might be of interest for testing the anti-inflammatory drugs aiming to prevent the inflammatory process and the development of emphysema.

Few studies have shown the protective role of pharmacological agents against the development of pulmonary emphysema until now, except for synthesized broad spectrum MMP inhibitors which are known to inhibit the MMP activity (Churg et al., 2007; Selman et al., 2003). Recently phosphodiesterase 4 inhibitors and some other agents as prostacyclin analog and clarithromycin have been reported to prevent emphysema in animals exposed to cigarette smoke (Chen et al., 2009; Mori et al., 2008; Nakanishi et al., 2009) but nothing is known about bronchodilators and the involved mechanisms still remain to be explored. The actions of these drugs upon the sub-acute or chronic phase of the inflammatory process are poorly documented.

$\beta_{2}$-adrenoceptor agonists are widely distributed on the resident and inflammatory cells implicated in pathological processes. Their efficacy to control the acute pulmonary inflammation has been revealed by studies in vitro and in vivo including a model of acute neutrophilic inflammation induced by cadmium (Hanania and Moore, 2004; Miyamoto et al., 2004; Whelan et al., 1993; Zhang et al., 2010). However, the long term effects elicited by $\beta_{2}$-adrenoceptor agonists against chronic inflammatory processes especially on the associated airspace enlargement have not been investigated and their properties in patients with COPD remain unclear (Hanania and Moore, 2004). To the best of our knowledge, the present work shows for the first time that formoterol alone and combined with ipratropium elicited an inhibitory effect on total cell and neutrophil numbers and on the cadmium-induced increased MMP-9 activity in bronchoalveolar lavage fluid accompanied with a protection against the cadmiuminduced airspace enlargement.

MMPs are known to be involved in the airway inflammation and remodelling associated with asthma and COPD (Demedts et al., 2005; Lagente et al., 2005). Various MMP inhibitors have been found to prevent lung injuries in several experimental models (Kim et al., 2006; Li et al., 2009; Nenan et al., 2007) especially in guinea pigs exposed to tobacco smoke (Selman et al., 2003) and in rats pretreated with ilomastat followed by a single or repeated exposures to cadmium (Fievez et al., 2006; Zhang et al., 2010). These studies demonstrate the important role played by MMPs in chronic neutrophilic inflammatory process and airspace enlargement particularly in this model. The key special role of MMP-9 is suggested by the correlation obtained in the present study between the MMP-9 activity with many other cytological, morphological and functional parameters as previously reported (Kirschvink et al., 2005). MMP-12 and the imbalance between MMPs and TIMP-1 as well as TIMP-2 also can contribute to pulmonary inflammation and development of emphysema (Abboud and Vimalanathan, 2008), however no increase in MMP-12, TIMP-1 and TIMP-2 was detected in bronchoalveolar lavage fluid in rats exposed to cadmium as found in a previous paper (Zhang et al., 2010). This suggests that these enzymes might not play a key role in this chronic pulmonary inflammation induced by repeated cadmium inhalation. Rationally, these parameters were no further investigated under the influence of tested drugs.

Although $\beta$-adrenoceptor agonists contribute to modulate the MMP9 activity in myocardial tissue (Patiyal and Katoch, 2005), their impact on pulmonary MMP activity is poorly documented. An up-regulated MMP-9 by salbutamol in vitro and in vivo in patients with acute respiratory distress syndrome has just been reported (O'Kane et al., 2009). Though formoterol is not an inhibitor of MMPs, the downregulation of MMP-9 activity accompanied with an inhibition of inflammatory responses by formoterol in rats exposed to a single dose of cadmium (Zhang et al., 2010) or for 5 weeks as in the present study reveals that formoterol might impair the inflammatory processes and tissue remodeling via an indirect inhibition of MMP-9 activity. The significant decrease elicited by formoterol in the number of neutrophils, known to be a major source of MMPs, could contribute to this effect on MMP-9 (Corbel et al., 2000). However, the inhibition on neutrophil secretory activity cannot be excluded and a direct influence on macrophages can be hypothesized. Our immunohistochemistry staining combined with the correlation between MMP-9 activity and macrophage number in $\mathrm{NaCl}$ and $\mathrm{Cd}$ pooled groups demonstrate that macrophages are a source of MMP-9 in our model as previously demonstrated in many species including human patients with COPD (Russell et al., 2002). Formoterol alone or combined to ipratropium exerting no direct inhibitory properties on MMP activity and despite the absence of impact of both drugs on the macrophage number, the MMP-9 
activity was decreased suggesting a possible direct inhibitory effect of these drugs on macrophage secretory activity of MMP-9.

Acetylcholine and its receptors have also been highlighted in vitro and in vivo to be involved in pulmonary inflammatory processes (Gosens et al., 2006). The inhibitory effects of atropine on diesel sootinduced neutrophilia (McQueen et al., 2007) and turpentine-induced leukocytic infiltration and tissue injury (Razani-Boroujerdi et al., 2008) have been demonstrated in rats. Recently, tiotropium has been reported to reduce allergen-induced airway inflammation in guinea pigs (Bos et al., 2007) and to reduce elastin degradation in patients with COPD (Ma et al., 2009). Our previous work also showed the protective effects against the cadmium-induced acute pulmonary inflammation in rats pretreated with ipratropium bromide (Zhang et al., 2010). Similar to the study showing a suppressive activity of tiotropium on MMP-2 production from lung fibroblasts (Asano et al., 2008), a significant reduction of MMP-9 activity in bronchoalveolar lavage fluid in ipratropium-pretreated rats with an acute pulmonary inflammation has been reported (Zhang et al., 2010). However, administration of ipratropium for 5 weeks had no effect on the inflammatory parameters measured in this study. The low concentration may be one explanation of its disability. Additionally, an inadequate frequency of administration may be another cause, since ipratropium is usually administered four times per day because its action sustains just for 4 to $6 \mathrm{~h}$ in clinical therapy. A desensitization of muscarinic receptors related to the 5 weeks of administration, a phenomenon classically reported for $\beta_{2}$-adrenoceptors which can be down-regulated or tolerant to stimulant effects in patients with asthma and COPD (Johnson, 2006) might not be excluded. The same mechanism could also explain why the anti-inflammatory properties elicited by both bronchodilators in the present study appear rather limited compared to their corresponding effects when administered once against the acute cadmium-induced lung injuries (Zhang et al., 2010). This hypothesis of a desensitization of $\beta_{2}$-adrenoceptors or muscarinic receptors was overturned by the results from the test aiming to investigate the change of airway responsiveness to methacholine after a single or a 5-week administration of both bronchodilators. The same bronchoprotective effects of formoterol or ipratropium bromide obtained whatever after a single or repeated administration of drugs excluded the desensitization of $\beta_{2}$-adrenoceptors and muscarinic receptors on airway smooth muscles. Since earlier studies have suggested that the desensitization of $\beta_{2}$ adrenoceptors appears more rapidly on inflammatory cells than on airway smooth muscles (Hanania and Moore, 2004; Johnson, 2006), another test was performed to determine whether the anti-inflammatory potency of both bronchodilators against the cadmiuminduced acute pulmonary inflammation decline after repeated exposures. A similar anti-inflammatory effect was found in both conditions, indicating no desensitization of receptors on inflammatory cells occurred in this model. Thus, other mechanisms may be responsible for the reduction of the effectiveness of both bronchodilators during the course of repeated cadmium administration, such as the down-regulated expression of $\beta$-adrenoceptors with the progression of the disease as documented in patients with COPD (Zhu et al., 2008) and the impairment of $\beta$-adrenoceptor-G(S)-protein-adenylate cyclase system as described by Abraham et al. (Abraham et al., 2006).

The reduction of airway resistance induced by the high concentration of formoterol and ipratropium suggests an occurrence of airway smooth muscles contraction and an increase in parasympathic tonus due to the cadmium inhalation.

In patients with COPD, it is well known that the combination of $\beta_{2}$-adrenoceptor agonists with anticholinergic agents exhibits synergistic effects on bronchodilation to improve lung function without additional side effects (Hanania, Donohue 2007). Recently, the combination of ICS with both types of bronchodilators is revealed to be more effective in controlling the COPD symptoms (Aaron et al., 2007; Welte et al., 2009). The present study showed a synergistic inhibition on the total cell and neutrophil counts in bronchoalveolar lavage fluid as well as on the increased MMP-9 activity associated with a reduced airspace enlargement. Though microscopic examination observed significant reduction of alveolar sizes, the less obvious but significant decrease in mean linear intercept is likely due to the limits of this index which can have a low sensitivity when emphysema is mild and not homogenous (Parameswaran et al., 2006). In literature, similar differences between mean linear intercept measured in healthy and emphysematous subject are recorded. While emphysema is clearly detected, the difference of mean linear intercept can remain rather limited (Thurlbeck, 1967). To the best of our knowledge, this is the first report concerning the synergistic effects of $\beta_{2}$-adrenoceptor agonists combined with anticholinergic agents on the chronic pulmonary inflammation and the airspace enlargement in an animal model.

Though cytokines are considered to be involved in the inflammatory response and development of emphysema (Barnes, 2004), the absence of detection of IL-1 $\beta$, TNF- $\alpha$ and GM-CSF in bronchoalveolar lavage fluid could be due to the methodological reasons as a mismatch between the sensitivity of tests and the levels of these substances or as an inadequacy between the sampling time and the kinetics of cytokines. Another possibility is that these mediators are not involved in the pathogenesis.

In conclusion, formoterol and ipratropium bromide protect the lungs against the airway obstruction induced by repeated cadmium inhalation. High concentration of formoterol exhibits an inhibition on the neutrophil number and MMP-9 activity as well as on airspace enlargement, while ipratropium has no anti-inflammatory effect. The combination of inefficient concentrations of ipratropium and formoterol exhibits a synergistic effect on these parameters. No desensitization of $\beta_{2}$-receptors and muscarinic receptors involved in airway smooth muscle contraction and in the inflammatory process occurs during this experimental course. Although it was a preclinical study, the results could provide evidence for further investigation of new therapeutic targets for currently used bronchodilators.

\section{Acknowledgements}

The authors thank Serge Bloden, Geneviève Keesemaecker and Philippes Dortu for their technical assistance.

This study was supported by the Walloon Region (DGTRE), Belgium and School of Medicine, Shanghai Jiaotong University, China.

\section{References}

Aaron, S.D., Vandemheen, K.L., Fergusson, D., Maltais, F., Bourbeau, J., Goldstein, R. Balter, M., O'Donnell, D., McIvor, A., Sharma, S., Bishop, G., Anthony, J., Cowie, R. Field, S., Hirsch, A., Hernandez, P., Rivington, R., Road, J., Hoffstein, V., Hodder, R. Marciniuk, D., McCormack, D., Fox, G., Cox, G., Prins, H.B., Ford, G., Bleskie, D., Doucette, S., Mayers, I., Chapman, K., Zamel, N., FitzGerald, M., 2007. Tiotropium in combination with placebo, salmeterol, or fluticasone-salmeterol for treatment of chronic obstructive pulmonary disease: a randomized trial. Ann. Intern. Med. 146, 545-555.

Abboud, R.T., Vimalanathan, S., 2008. Pathogenesis of COPD. Part I. The role of proteaseantiprotease imbalance in emphysema. Int. J. Tuberc. Lung Dis. 12, 361-367.

Abraham, G., Kottke, C., Dhein, S., Ungemach, F.R., 2006. Agonist-independent alteration in beta-adrenoceptor-G-protein-adenylate cyclase system in an equine model of recurrent airway obstruction. Pulm. Pharmacol. Ther. 19, 218-229.

Asano, K., Shikama, Y., Shibuya, Y., Nakajima, H., Kanai, K., Yamada, N., Suzaki, H., 2008 Suppressive activity of tiotropium bromide on matrix metalloproteinase production from lung fibroblasts in vitro. Int I Chron Obstruct Pulmon Dis 3, 781-789.

Barnes, P.J., 2004. Mediators of chronic obstructive pulmonary disease. Pharmacol. Rev. $56,515-548$.

Bos, I.S., Gosens, R., Zuidhof, A.B., Schaafsma, D., Halayko, A.J., Meurs, H., Zaagsma, J. 2007. Inhibition of allergen-induced airway remodelling by tiotropium and budesonide: a comparison. Eur. Respir. J. 30, 653-661.

Cazzola, M., Dahl, R., 2004. Inhaled combination therapy with long-acting beta 2 agonists and corticosteroids in stable COPD. Chest 126, 220-237.

Chen, Y., Hanaoka, M., Chen, P., Droma, Y., Voelkel, N.F., Kubo, K., 2009. Protective effect of beraprost sodium, a stable prostacyclin analog, in the development of cigarette smoke extract-induced emphysema. Am. J. Physiol. Lung Cell. Mol. Physiol. 296, L648-656. 
Churg, A., Wang, R., Wang, X., Onnervik, P.O., Thim, K., Wright, J.L., 2007. Effect of an MMP-9/MMP-12 inhibitor on smoke-induced emphysema and airway remodelling in guinea pigs. Thorax 62, 706-713.

Corbel, M., Boichot, E., Lagente, V., 2000. Role of gelatinases MMP-2 and MMP-9 in tissue remodeling following acute lung injury. Braz. J. Med. Biol. Res. 33, 749-754.

D'Hulst, A.I., Vermaelen, K.Y., Brusselle, G.G., Joos, G.F., Pauwels, R.A., 2005. Time course of cigarette smoke-induced pulmonary inflammation in mice. Eur. Respir. J. 26, 204-213.

Demedts, I.K., Brusselle, G.G., Bracke, K.R., Vermaelen, K.Y., Pauwels, R.A., 2005. Matrix metalloproteinases in asthma and COPD. Curr. Opin. Pharmacol. 5, 257-263.

Fievez, L., Kirschvink, N., Belleflamme, M., Lagente, V., Gustin, P., 2006. Effects of the MMP inhibitor GM-6001 on emphysema development, inflammation and MMPs activity induced by cadmium in rats. Fundam. Clin. Pharmacol. 20, 194.

Gosens, R., Zaagsma, J., Meurs, H., Halayko, A.J., 2006. Muscarinic receptor signaling in the pathophysiology of asthma and COPD. Respir. Res. 7, 73.

Hanania, N.A., Donohue, J.F., 2007. Pharmacologic interventions in chronic obstructive pulmonary disease: bronchodilators. Proc. Am. Thorac Soc. 4, 526-534.

Hanania, N.A., Moore, R.H., 2004. Anti-inflammatory activities of beta2-agonists. Curr. Drug Targets Inflamm. Allergy 3, 271-277.

Hoidal, J.R., Niewoehner, D.E., Rao, N.V., Hibbs, M.S., 1985. The role of neutrophils in the development of cadmium chloride-induced emphysema in lathyrogen-fed hamsters. Am. J. Pathol. 120, 22-29.

Johnson, M., 2006. Molecular mechanisms of beta(2)-adrenergic receptor function, response, and regulation. J. Allergy Clin. Immunol. 117, 18-24 quiz 25.

Jones, P.W., 2009. Triple therapy for chronic obstructive pulmonary disease: trials catching up with clinical practice? Am. J. Respir. Crit. Care Med. 180, 689-690.

Kim, J.H., Suk, M.H., Yoon, D.W., Lee, S.H., Hur, G.Y., Jung, K.H., Jeong, H.C., Lee, S.Y., Suh, I.B., Shin, C., Shim, J.J., In, K.H., Yoo, S.H., Kang, K.H., 2006. Inhibition of matrix metalloproteinase-9 prevents neutrophilic inflammation in ventilator-induced lung injury. Am. J. Physiol. Lung Cell. Mol. Physiol. 291, L580-587.

Kirschvink, N., Leemans, J., Delvaux, F., Snaps, F., Clercx, C., Gustin, P., 2007. Noninvasive assessment of airway responsiveness in healthy and allergen-sensitised cats by use of barometric whole body plethysmography. Vet. J. 173, 343-352.

Kirschvink, N., Vincke, G., Fievez, L., Onclinx, C., Wirth, D., Belleflamme, M., Louis, R. Cataldo, D., Peck, M.J., Gustin, P., 2005. Repeated cadmium nebulizations induce pulmonary MMP-2 and MMP-9 production and emphysema in rats. Toxicology 211, 36-48.

Lagente, V., Manoury, B., Nenan, S., Le Quement, C., Martin-Chouly, C., Boichot, E., 2005 Role of matrix metalloproteinases in the development of airway inflammation and remodeling. Braz. J. Med. Biol. Res. 38, 1521-1530.

Li, W., Li, J., Wu, Y., Wu, J., Hotchandani, R., Cunningham, K., McFadyen, I., Bard, J., Morgan, P., Schlerman, F., Xu, X., Tam, S., Goldman, S.J., Williams, C., Sypek, J. Mansour, T.S., 2009. A selective matrix metalloprotease 12 inhibitor for potential treatment of chronic obstructive pulmonary disease (COPD): discovery of (S)-2-(8(methoxycarbonylamino)dibenzo[b, d]furan-3-sulfonamido)-3-methylbu tanoic acid (MMP408). J. Med. Chem. 52, 1799-1802.

Ma, S., Lin, Y.Y., Tartell, L., Turino, G.M., 2009. The effect of tiotropium therapy on markers of elastin degradation in COPD. Respir. Res. 10, 12.

Mannino, D.M., Holguin, F., Greves, H.M., Savage-Brown, A., Stock, A.L., Jones, R.L., 2004 Urinary cadmium levels predict lower lung function in current and former smokers: data from the Third National Health and Nutrition Examination Survey. Thorax 59, 194-198.

McQueen, D.S., Donaldson, K., Bond, S.M., McNeilly, J.D., Newman, S., Barton, N.J., Duffin, R. 2007. Bilateral vagotomy or atropine pre-treatment reduces experimental diesel-soot induced lung inflammation. Toxicol. Appl. Pharmacol. 219, 62-71.

Miyamoto, M., Tomaki, M., Lotvall, J., Linden, A., 2004. Beta-adrenoceptor stimulation and neutrophil accumulation in mouse airways. Eur. Respir. J. 24, 231-237.

Molfino, N.A., Jeffery, P.K., 2007. Chronic obstructive pulmonary disease: histopathology, inflammation and potential therapies. Pulm. Pharmacol. Ther. 20, 462-472.
Mori, H., Nose, T. Ishitani, K. Kasagi, S, Souma, S, Akiyoshi, T, Kodama, Y., Mori, T., Kondo, M., Sasaki, S., Iwase, A., Takahashi, K., Fukuchi, Y., Seyama, K., 2008. Phosphodiesterase 4 inhibitor GPD-1116 markedly attenuates the development of cigarette smoke-induced emphysema in senescence-accelerated mice P1 strain. Am. J. Physiol. Lung Cell. Mol. Physiol. 294, L196-204.

Mortaz, E., Rad, M.V., Johnson, M., Raats, D., Nijkamp, F.P., Folkerts, G., 2008. Salmeterol with fluticasone enhances the suppression of IL-8 release and increases the translocation of glucocorticoid receptor by human neutrophils stimulated with cigarette smoke. J. Mol. Med. 86, 1045-1056.

Nakanishi, Y., Kobayashi, D., Asano, Y., Sakurai, T., Kashimura, M., Okuyama, S., Yoneda, Y., Shapiro, S.D., Takayama, K., 2009. Clarithromycin prevents smoke-induced emphysema in mice. Am. J. Respir. Crit. Care Med. 179, 271-278.

Nenan, S., Lagente, V., Planquois, J.M., Hitier, S., Berna, P., Bertrand, C.P., Boichot, E., 2007. Metalloelastase (MMP-12) induced inflammatory response in mice airways: effects of dexamethasone, rolipram and marimastat. Eur. J. Pharmacol. 559, 75-81.

O'Kane, C.M., McKeown, S.W., Perkins, G.D., Bassford, C.R., Gao, F., Thickett, D.R., McAuley, D.F., 2009. Salbutamol up-regulates matrix metalloproteinase-9 in the alveolar space in the acute respiratory distress syndrome. Crit. Care Med. 37, 2242-2249.

Parameswaran, H., Majumdar, A., Ito, S., Alencar, A.M., Suki, B., 2006. Quantitative characterization of airspace enlargement in emphysema. J. Appl. Physiol. 100, 186-193.

Patiyal, S.N., Katoch, S.S., 2005. Beta-adrenoceptor agonist clenbuterol down-regulates matrix metalloproteinase (MMP-9) and results in an impairment of collagen turnover in mice left ventricle. Jpn J. Physiol. 55, 165-172.

Powrie, D.J., Wilkinson, T.M., Donaldson, G.C., Jones, P., Scrine, K., Viel, K., Kesten, S., Wedzicha, J.A., 2007. Effect of tiotropium on sputum and serum inflammatory markers and exacerbations in COPD. Eur. Respir. J. 30, 472-478.

Profita, M. Giorgi, R.D. Sala, A. Bonanno, A. Riccobono, L. Mirabella, F. Gjomarkaj, M. Bonsignore, G., Bousquet, J., Vignola, A.M., 2005. Muscarinic receptors, leukotriene B4 production and neutrophilic inflammation in COPD patients. Allergy 60, 1361-1369.

Razani-Boroujerdi, S., Behl, M., Hahn, F.F., Pena-Philippides, J.C., Hutt, J., Sopori, M.L., 2008. Role of muscarinic receptors in the regulation of immune and inflammatory responses. J. Neuroimmunol. 194, 83-88.

Russell, R.E., Culpitt, S.V., DeMatos, C., Donnelly, L., Smith, M., Wiggins, J., Barnes, P.J., 2002. Release and activity of matrix metalloproteinase- 9 and tissue inhibitor of metalloproteinase- 1 by alveolar macrophages from patients with chronic obstructive pulmonary disease. Am. J. Respir. Cell Mol. Biol. 26, 602-609.

Selman, M., Cisneros-Lira, J., Gaxiola, M., Ramirez, R., Kudlacz, E.M., Mitchell, P.G., Pardo, A., 2003. Matrix metalloproteinases inhibition attenuates tobacco smoke-induced emphysema in Guinea pigs. Chest 123, 1633-1641.

Thurlbeck, W., 1967. Internal surface area and other measurements in emphysema. Thorax 22, 483-496.

Welte, T., Miravitlles, M., Hernandez, P., Eriksson, G., Peterson, S., Polanowski, T., Kessler, R., 2009. Efficacy and tolerability of budesonide/formoterol added to tiotropium in patients with chronic obstructive pulmonary disease. Am. J. Respir. Crit. Care Med. 180, 741-750.

Whelan, C.J., Johnson, M., Vardey, C.J., 1993. Comparison of the anti-inflammatory properties of formoterol, salbutamol and salmeterol in guinea-pig skin and lung. $\mathrm{Br}$. J. Pharmacol. 110, 613-618.

Zhang, W., Fievez, L., Cheu, E., Bureau, F., Rong, W., Zhang, F., Zhang, Y., Advenier, C., Gustin, P., 2010. Anti-inflammatory effects of formoterol and ipratropium bromide against acute cadmium-induced pulmonary inflammation in rats. Eur. J. Pharmacol. 628, 171-178.

Zhu, W.J., He, B., Xu, M., 2008. Expression and significance of beta(2)-adrenoreceptor in inflammatory cells of patients with chronic obstructive pulmonary disease. Zhonghua Yi Xue Za Zhi 88, 2099-2102. 